\title{
Optimizing the lignin based synthesis of flexible polyurethane foams employing reactive liquefying agents
}

\author{
Jacopo Bernardini ${ }^{1}$, Irene Anguillesi ${ }^{1}$, Maria-Beatrice Coltelli ${ }^{1}$, Patrizia Cinelli ${ }^{2}$, Andrea \\ Lazzeri $^{1 *}$ \\ ${ }^{1}$ Department of Civil and Industrial Engineering, University of Pisa, Largo L. Lazzarino 1, \\ 56126, Pisa \\ ${ }^{2}$ National Interuniversity Consortium of Materials Science and Technology (INSTM), Via G. \\ Giusti, 9, 50121, Firenze, Italy \\ *Corresponding author. Tel.: +39 0502217807; fax: +39 0502217866. \\ E-mail address: a.lazzeri@ing.unipi.it (A. Lazzeri).
}

This article has been accepted for publication and undergone full peer review but has not been through the copyediting, typesetting, pagination and proofreading process, which may lead to differences between this version and the Version of Record. Please cite this article as doi: 10.1002/pi.4905 


\begin{abstract}
The present work is focused on the optimization of a green process based on the employment of by-products obtained from wood treatments as raw materials for producing flexible polyurethanes foams. More specifically, lignin was employed in flexible polyurethane foams in order to partially replace the usual fossil polyols; therefore glycerol (GLY) and glycerin polyglycidyl ether (EJ 300) were used as a polyol fraction for lignin liquefaction. Polypropylene glycol triol was used as a chain extender in different ratios with liquefaction solvents, and polymeric diphenylmethane diisocyanate (PMDI) as an isocyanate fraction. Liquefaction of lignin was performed by microwave irradiation, thus reducing the processing time and energy required compared to present industrial production processes. All the foams were produced in controlled expansion through the adoption of a "one-shot" approach, using water as a blowing agent and having an isocyanate index $(\mathrm{NCO} / \mathrm{OH})$ of less than 100 to improve the flexibility of the foam. This approach allowed for the substitution of up to $12 \%$ of common petro derived polyol with commercial soda lignin. Finally, the foams were characterized, presenting properties that could be modulated as a function of lignin content, GLY/EJ300 ratio and isocyanate index. The qualities of the foams were compatible with existing materials used for furniture and for the interiors of car seats and couches.
\end{abstract}

Keywords: Polyurethane, lignin, flexible foam, microwave, renewable sources, green chemistry.

\title{
Introduction
}

Polyurethanes (PUs) are a wide class of polymers that are synthesized through a polyaddition reaction between a glycol or, more commonly, a polyol, and a di- or polyisocyanate forming 
urethanic linkages. Thanks to the possibility of employing reagents with a flexible or rigid structure, and thereby controlling the structural rigidity of the final material, these polymers are well-known for their versatility and are employed in the industrial production of foams, sheets, elastomers, adhesives, paints, etc.

Foams are commonly classified as being rigid or flexible, depending on their apparent density and mechanical properties. Flexible foams represent the largest market among polyurethane products in strategic sectors, such as furniture and automotive industries (cushioning, bumpers, etc.).

Polyurethane materials employed in foams usually consist of block copolymers. In fact, long chain flexible polyols that allow flexibility (resulting in soft blocks) and rigid aromatic polyisocyanates that impart stiffness (resulting in hard blocks) are usually employed.

Therefore, polyurethane foam properties can be modulated by adapting the composition and the ratio of these blocks.

Currently, polyurethanes are mainly synthesized starting from petrochemical polyols, but many studies were carried out over the last decades in order to replace them with renewable sources, such as natural vegetable oils ${ }^{1-4}$ and epoxidized oils ${ }^{5-6}$.

As a partial alternative to polyols, lignin, being the second most abundant biopolymer after cellulose $^{7}$, can be used as a raw material for the synthesis of polyurethane foams. It was employed as such, or chemically modified $^{8-9}$, in order to prepare polyesters and polyurethanes, thus exploiting the reactivity of its phenolic and aliphatic hydroxyl groups ${ }^{10-12}$. These groups are also responsible of the anti-oxidant activity of lignin derivatives ${ }^{13}$. Lignin is an aromatic complex polymer that is highly branched and composed of subunits of alcohol 4-hydroxycinnamyl (p-coumaryl alcohol), and its methoxylated derivatives are in positions 3- and 3,5- (called coniferyl alcohol and sinapyl alcohol, respectively) ${ }^{14-15}$. This natural polymer has a molecular weight of about 3000-7000 g/mol. 
Presently, there are many different types of lignin, whose nature depends on the different preliminary treatments which it has undergone ${ }^{16}$. Lignin is commonly considered a waste material ${ }^{17}$ of wood pulping and papermaking operations, but only a small amount of it (about $2 \%)$ is recovered and employed to produce other chemicals ${ }^{18-19}$. These pulping treatments supply fragmented lignin, therefore increasing its reactivity owing to lower molecular weights and, mostly, higher solubility in organic solvents. Soda pulping is the oldest treatment and is commonly used for obtaining lignin from non-woody materials; this kind of lignin is sulphur-free and has a low molecular weight, a high content of phenolic hydroxyl groups, and a low content of residual sugars and ashes.

Nowadays, not much success has been reported in the preparation of flexible foams based on liquefied lignin, probably because the rigid structure of lignin is difficult to be inserted in a flexible material. However the introduction of lignin in flexible foams even in reduced amount (about $10-20 \%$ by weight) can be interesting because the worldwide market volume of flexible foams is wider than the one of rigid foams ${ }^{20}$. Hatakeyama ${ }^{21}$ and his co-workers studied several lignins, such as Kraft, organosolv and sulphonate, by dissolving them in oligoether diols in order to obtain a liquid mixture. By using the macrodiol as both the solvent and comonomer, they improved the reactivity of lignin's hydroxyl groups; the use of macrodiol allows for the introduction of flexible oligoether as a spacer among the aromatic domains, thus reducing the stiffness of the chain. Lignosulfonate materials from sulphite pulping $^{22}$ and Kraft lignin were used to prepare rigid polyurethane foams ${ }^{23}$, whereas recently flexible foams were successfully synthesized by Cinelli et al. ${ }^{24}$ with a green synthesis approach based on the use of glycerol, polyethylene glycol and microwave heating. Initially, microwaves were investigated in the degradation of hazardous compounds ${ }^{25}$, then it was extended to lignocellulosic biomass ${ }^{26-27}$ in order to obtain liquid polyols with shorter reaction times, thus reducing energy consumption. This approach was experimented on commercial 
lignin, and the final mixture contained a greater amount of phenolic $\mathrm{OH}$ groups and fewer methoxy groups, thus improving system reactivity ${ }^{28}$. Microwaves are able to penetrate and heat the reaction medium, thereby reducing reaction times from hours to minutes; furthermore, through microwave heating, a rapid increase of temperature and a lower thermal degradation of reagents are achieved when compared to traditional heating systems ${ }^{12,29}$.

Currently, microwaves heating technique has been extended up to pilot scale and scale-up has been restricted by a lack of demonstrated effectiveness and a need for sophisticated equipment. The control of operating parameters such as radiation time, power, cavity design and material throughput is important to scale-up the microwaves. Although the initial capital cost of microwave equipment is high, this can be offset by economic benefits attained in operation by process time saving and environmental compatibility ${ }^{30}$.

In general, the liquefaction process of lignocellulosic biomass in solvents has been widely studied $^{31-32}$. The liquefaction process results in mixtures rich in oligomers, due to the cleavage of $\beta$ 1-4 glycosidic bonds of cellulosic and lignin fractions ${ }^{33-34}$. The use of glycerol as a liquefying agent of lignin is necessary because of its efficiency ${ }^{24}$, but in the successive formation of polyurethanes results in a high crosslinking degree leading towards rigid foams. In a previous ${ }^{24}$ work a long chain liquid glycol (polyethylene glycol, PEG) was used in the liquefying mixture as a carrier agent to limit this effect. However, in the present work an attempt was made to replace this glycol with a low cost product consisting in a mixture of diglycidyl and tri-glycidyl ether of glycerol (commercialized as glycerin polyglycidyl ether). This mixture has a higher potential reactivity than PEG, but is more flexible than glycerol. Moreover, being it not a nucleophile but an electrophile, its reactivity as liquefying agent is dormant and it can be activated by glycerol thus forming a liquefaction agent having a more flexible structure than glycerol and thus more suitable for flexible foams. Moreover, as the epoxide compounds can also result in grafting on lignin, lignin fragments with flexible 
branched dangling chains can be obtained by this method, introducing some advancements with respect to the use of not reactive PEG.

In fact, lignin was liquefied through microwave irradiation by using both glycerin and glycerin polyglycidyl ether, and the resulting mixture was used as a polyol fraction to produce flexible polyurethane foams using a one-shot approach. The process was investigated as a function of the reagent composition, and the foams were characterized in terms of morphology and thermo-mechanical properties.

\section{Experimental part}

\section{Materials}

The lignin used was Protobind ${ }^{\mathrm{TM}}$ 1000, produced in dry powder form by ALM India Pvt. Ltd. using a patented technology of Green Value SA; this lignin comes from soda pulping of nonwoody biomass and therefore is a soda lignin. Protobind ${ }^{\mathrm{TM}} 1000$ has a high degree of purity (about $98 \%$ ) and is free of hemicellulose. Glycerol from Aldrich and Glyether ${ }^{\circledR}$ EJ-300 (EJ 300, glycerin polyglycidyl ether) from JSI Group Ltd. were used as solvents to liquefy lignin in a microwave oven. Polypropylene glycol triol (PPG triol), purchased by Sigma Chemicals, was used as a chain extender; it has a molecular weight of 4800, a functionality of 2.6, and viscosity of $850 \mathrm{mPas}$ at $25^{\circ} \mathrm{C}$. The structures of these chemicals are reported in Figure 1.

The polyisocyanate used was Elastogran ISO 116/1, a polymeric diphenylmethane diisocyanate (PMDI) having a $25.7 \mathrm{wt} \%$ of NCO content, and was provided by BASF Poliuretani Italia Spa. The isocyanate was added in excess with respect to the $\mathrm{OH}$ groups on the polyols in order to react with distilled water, thus forming $\mathrm{CO}_{2}$ which acted as the foam blowing agent. Both gelling and blowing catalysts were used, while keeping them in an appropriate balance in order to obtain the desired products. The catalysts used were kindly provided by Air Products and belong to new generation catalysts (NE) having a low emission 
of amine: $\mathrm{DABCO}^{\circledR} \mathrm{NE1070}$ (3-dimethylaminopropyl urea, gelling agent) and $\mathrm{DABCO}{ }^{\circledR}$ NE300 ( $N$ - [2- [2-(dimethylamino)ethoxy] ethyl]- $N$-methyl-1,3-propanediamine, blowing agent). These particular catalysts can reduce emissions since their molecules can chemically bind themselves to the polyurethane matrix and therefore not be released during the foaming process. DABCO ${ }^{\circledR}$ DC2525, a silicone surfactant made from $70 \%$ by weight of polysiloxane provided by Air Products, was used to guarantee the uniformity of the foam structure and to enhance the cell opening.

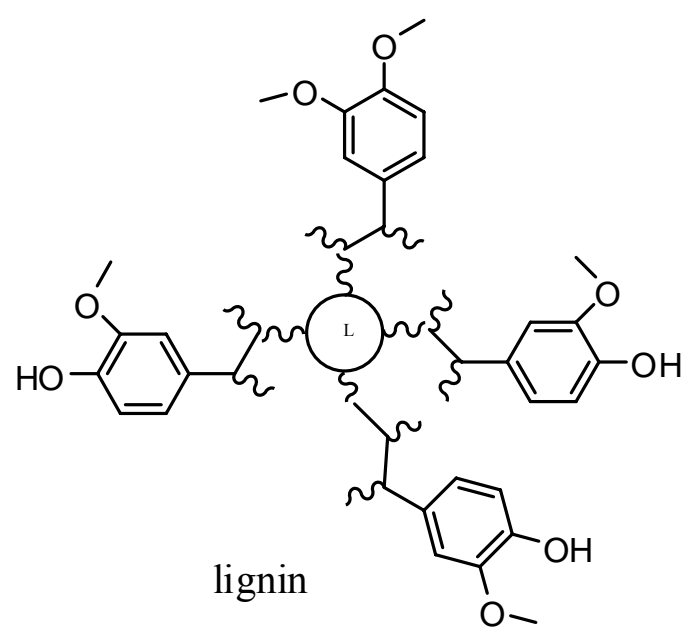

\section{LIQUEFYING AGENTS}

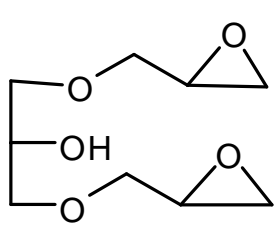<smiles></smiles><smiles>OCC(O)CO</smiles>

GLYCEROL

EJ 300

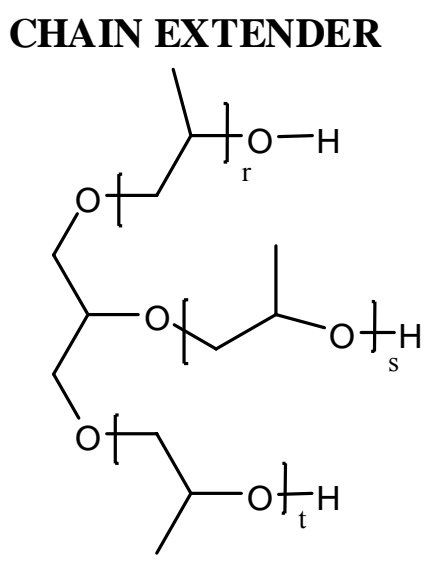

PPG triol

Figure 1. Structure of the main molecules used in the polyol fraction 


\section{Liquefaction of lignin}

Lignin samples were dried for 24 hours in an oven with air circulating at $80{ }^{\circ} \mathrm{C}$. Lignin was then mixed with liquefying polyols (glycerol and EJ 300) at predetermined weight ratios (Table 1) and placed in a Teflon vessel, which volume is $100 \mathrm{ml}$, to undergo liquefaction treatment in a multimode microwave oven CEM MDS 2100. A heat power was set to about $200 \mathrm{~W}$ in order to reach $140{ }^{\circ} \mathrm{C}$ in 2 minutes, then the trial was stopped. The dark viscous liquid was employed without any further purification.

\section{Foam preparation}

The liquefied mixture was mixed with the other polyol components and the polyisocyanate; the resulting mixture was deposited into a mold $(85 \times 85 \times 55 \mathrm{~mm})$, which was closed thus allowing controlled expansion. The three main reactions involved in the foam production are reported in Figure 2.
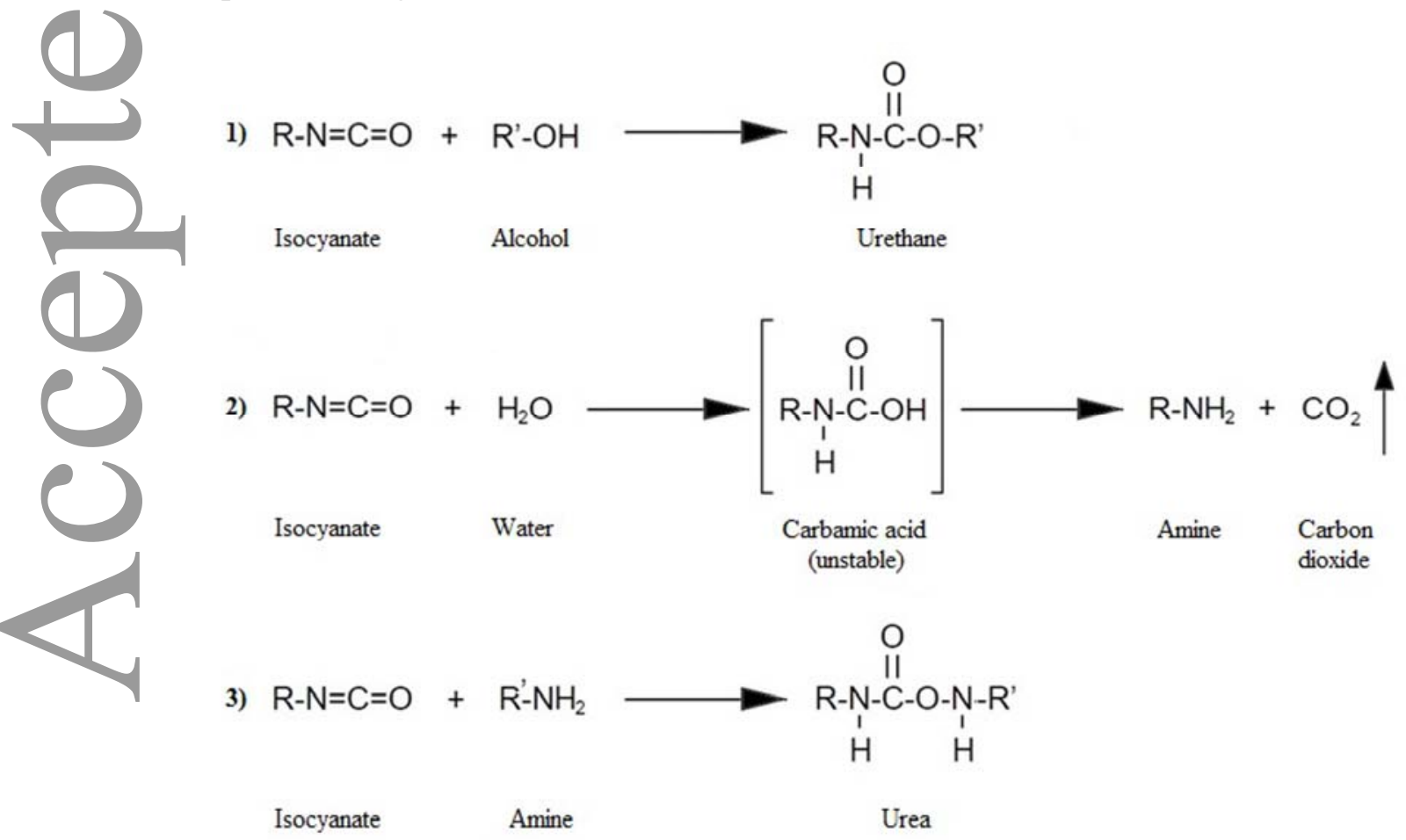

Figure 2. Main reactions of polyurethane production.

A schematic pathway of the process is reported in Figure 3. 


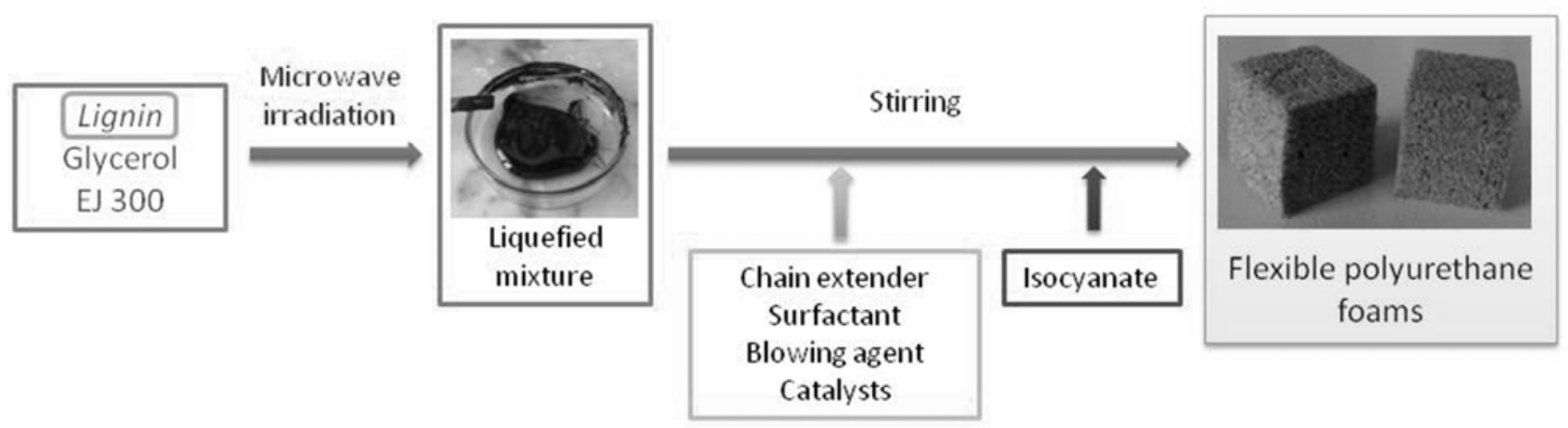

Figure 3. Schematic pathway for the synthesis of polyurethane foams starting from commercial lignin by adopting the "one-shot" approach.

The "one-shot" process is the most direct and economical method for producing polyurethane foam, adding all the components at once thus reducing the mixing times and, consequently, the production times.

The differences among the five studied formulations consisted of the polyol content in the liquefaction mixture. The polyisocyanate was added in a sufficient quantity in order to achieve the desired Isocyanate Index. The Isocyanate value varied in range from 60 to 85 for the five formulations, and the trials indicated as $\mathrm{XY}$, where $\mathrm{X}$ is $\mathrm{A}, \mathrm{B}, \mathrm{C}, \mathrm{D}$ or $\mathrm{E}$ (liquefaction mixture) and $\mathrm{Y}$ can be $60,65,70,75,80$ or 85 (Isocyanate Index). The compositions of the mixtures prepared to synthesize the foams are reported in Table 1. The polyisocyanate amount and lignin percentage change on the basis of the selected $\mathrm{NCO} / \mathrm{OH}$ ratio.

All the foams produced were maintained at room temperature for a minimum of 3 days before characterization.

\section{Methods}

The hydroxyl numbers of the polyolic mixture was determined by following the ASTM D 2849-69 norm: $1 \mathrm{~g}$ of liquefied lignin and $1.25 \mathrm{~g}$ of PPG triol were added to $25 \mathrm{ml}$ of phthalate reagent and heated for $20 \mathrm{~min}$ at $110{ }^{\circ} \mathrm{C}$. This mixture was added to $50 \mathrm{ml}$ of pure 1,4-dioxane, $25 \mathrm{ml}$ of distilled water, and then the resulting mixture was titrated with $1 \mathrm{M}$ of sodium hydroxide solution up to equivalence point. The phthalate reagent was a mixture of 
$150 \mathrm{~g}$ of phthalic anhydride, $24.2 \mathrm{~g}$ of imidazole and $1000 \mathrm{~g}$ of pure 1,4-dioxane. The hydroxyl number in $\mathrm{mgKOH} / \mathrm{g}$ of the sample was calculated by the following equation:

Hydroxyl number $(\mathrm{OH})=\frac{[(B-A) N]}{W}$

where $A$ is the volume of the $\mathrm{NaOH}$ solution required for titration of the sample mixture of liquefied lignin and the chain extender $(\mathrm{ml}), B$ is the volume of blank solution $(\mathrm{ml}), N$ is the normal concentration of sodium hydroxide, and $W$ is the weight $(\mathrm{g})$ of the sample mixture of liquefied lignin and the chain extender. The results are reported in Table 2.

The amount of isocyanate required was estimated using the following equation:

$$
\frac{N C O}{O H}=\frac{M_{N C O} W_{N C O}}{\left[M_{O H} W_{O H}+\sum_{i=1}^{3} M_{A d i} W_{A d i}+\left(\frac{2}{18}\right) W_{H_{2} O}\right]} \cdot 100
$$

where $M_{N C O}$ is the number of isocyanate groups in one gram of isocyanate, $W_{N C O}$ is the weight of isocyanate $(\mathrm{g}), M_{O H}$ is the number of hydroxyl groups contained in one gram of polyol (mixture of liquefied lignin and chain extender), $W_{O H}$ is the weight of polyols $(\mathrm{g})$, $M_{A d_{i}}$ is the number of hydroxyl groups in one gram of additives (blowing catalyst, index 1, gelling catalyst, index 2 , and surfactant, index 3$), W_{A d_{i}}$ is the weight of additives (g), and $W_{\mathrm{H}_{2} \mathrm{O}}$ is the weight of water.

The FT-IR characterization was performed with a Thermo Scientific Nicolet 380; the foams were formerly dried at $110{ }^{\circ} \mathrm{C}$ for 3 hours in order to avoid the presence of absorbed water in the material. The foams were sampled on the center of the specimen and dried once again at $105{ }^{\circ} \mathrm{C}$ for 2 hours before analysis; for each sample, 128 scans were done in a range from 4000 to $400 \mathrm{~cm}^{-1}$.

Thermogravimetric analysis (TGA) measurements were made following the ASTM standard procedure D 3850-94 by using a Rheometric Scientific Instrument apparatus. The samples 
were shredded into a fine powder before measurement and were heated from room temperature to $900{ }^{\circ} \mathrm{C}$ at a rate of $10{ }^{\circ} \mathrm{C} / \mathrm{min}$ under air atmosphere.

For dynamic mechanical thermo analysis (DMTA), the foam samples were trimmed in $20 \mathrm{x}$ $20 \times 20 \mathrm{~mm}$ cubes and subsequently tested following the compression method described in the ASTM D 3574-05 standard procedure with a Gabo Eplexor $100 \mathrm{~N}$ device. The cubes were placed between two parallel plates with a $25 \mathrm{~mm}$ diameter; storage modulus $\left(E_{0}\right)$ and $\tan \delta$ values were measured at a frequency of $1 \mathrm{~Hz}$ from -150 to $120^{\circ} \mathrm{C}$. The temperature rate was fixed at $2{ }^{\circ} \mathrm{C} / \mathrm{min}$; the skip showed is said damping and was associated with the glass transition temperature of soft domains.

Based on this norm, also the apparent density and compression force deflection $(C F D V)$ at $50 \%$ of the thickness were measured. The sample size was $30 \times 30 \times 30 \mathrm{~mm}$, and the apparent density was the ratio between the weight $(\mathrm{M})$ and volume $(\mathrm{V})$ of the specimens, which should be expressed in $\mathrm{Kg} / \mathrm{m}^{3}$.

The compression force deflection test was carried out using an Instron 1185, according to standard procedure: (1) pre-compress the sample up to $75 \%$ and subsequently to $80 \%$ of its original thickness at $4 \mathrm{~mm} / \mathrm{s}$, without relax between the two steps; (2) rest for 6 minutes and then measure the thickness of the sample; (3) bring the specimen into contact with the compression plates and apply a contact load of $140 \mathrm{~Pa}$; (4) compress the specimen until 50\% of its thickness at $0,83 \mathrm{~mm} / \mathrm{s}$ and observe the final load after 60 seconds. At least three replicates were tested for each sample. Compression strength was calculated as the ratio of the final compression load at $50 \%$ of the thickness after $60 \mathrm{~s}(\mathrm{~N})$ and the cross section area of the specimen $\left(\mathrm{mm}^{2}\right)$.

A Scanning Electron Microscope (SEM) Joel JSM5600LV was used to study the morphology of samples sputtered using an Edwards Sputter Coater.

\section{Results and discussion}

This article is protected by copyright. All rights reserved 


\section{Production of liquefied lignin}

The solid powder lignin has been liquefied in suitable reagents, GLY and EJ 300, by following an internal method that had been previously developed ${ }^{12,24}$. Liquefaction, carried out by microwave irradiation, was optimized by increasing the amount of liquefaction solvents (glycerol and EJ 300) with the aim of reducing the viscosity of the polyolic mixture, to compensate for increasing the lignin content.

The $\mathrm{OH}$ number of the starting liquefied mixture is one of the most important parameters in polyurethane foam production, therefore it was determined following the abovementioned ASTM D2849-69 norm. This method demands a long esterification time, but it is possible to reduce the reaction time through the addition of imidazole as a catalyst ${ }^{31}$. Following this standard method, a good evaluation of the $\mathrm{OH}$ value was obtained, both for the liquefied lignin and also for the liquefied lignin/chain extender mixture (Table 2).

The EJ300 consists of a mixture of di- and tri- glycidyl ether of glycerol. The epoxide groups are activated by hydroxyl compounds above $60^{\circ} \mathrm{C}^{35}$ through the reaction reported in Figure 4 , if $\mathrm{R}_{2^{-}}$is a glycerol deriving structure. As the $\mathrm{pH}$ of the liquefying mixture is close to neutrality, the nucleophilic attack of glycerol onto the epoxide ring would result in the formation of the two products reported in Figure 4. Thus the products of the reaction are hydroxyl compounds. This explains how EJ300 can have a liquefying activity. The same reaction where $R_{2}$ - represents the lignin structure can explain how EJ300 can graft to lignin thus modifying it by the grafting of flexible chains of at least 12 atoms with at least an epoxide terminal. 

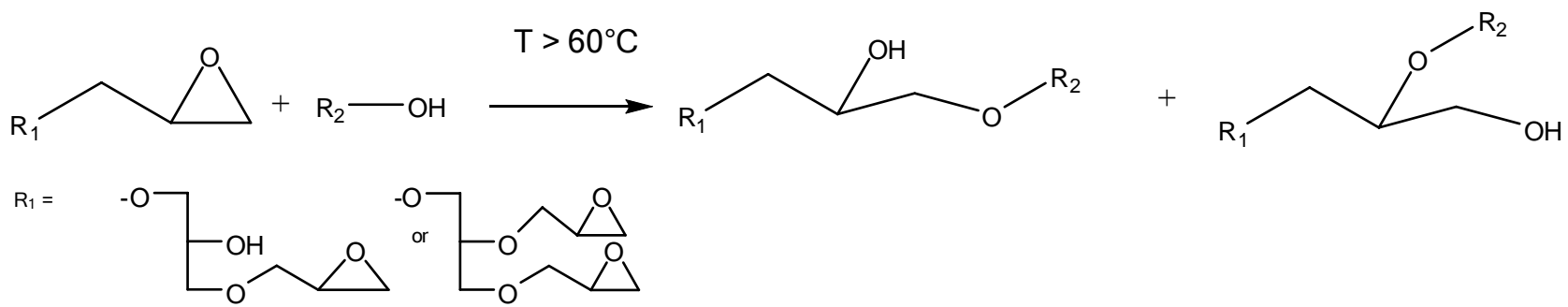

$\mathrm{R}_{2}=$ lignin or glycerol structure

Figure 4. Reaction between EJ300 with glycerol or lignin during liquefaction.

The $\mathrm{OH}$ value is reported as a function of the EJ300/glycerol weight ratio in Figure 5. Interestingly, the trend shows a maximum of EJ300/glycerol ratio of about 2,5 which is close to the ratio between the average molecular weight of EJ300 and the molecular weight of glycerol.

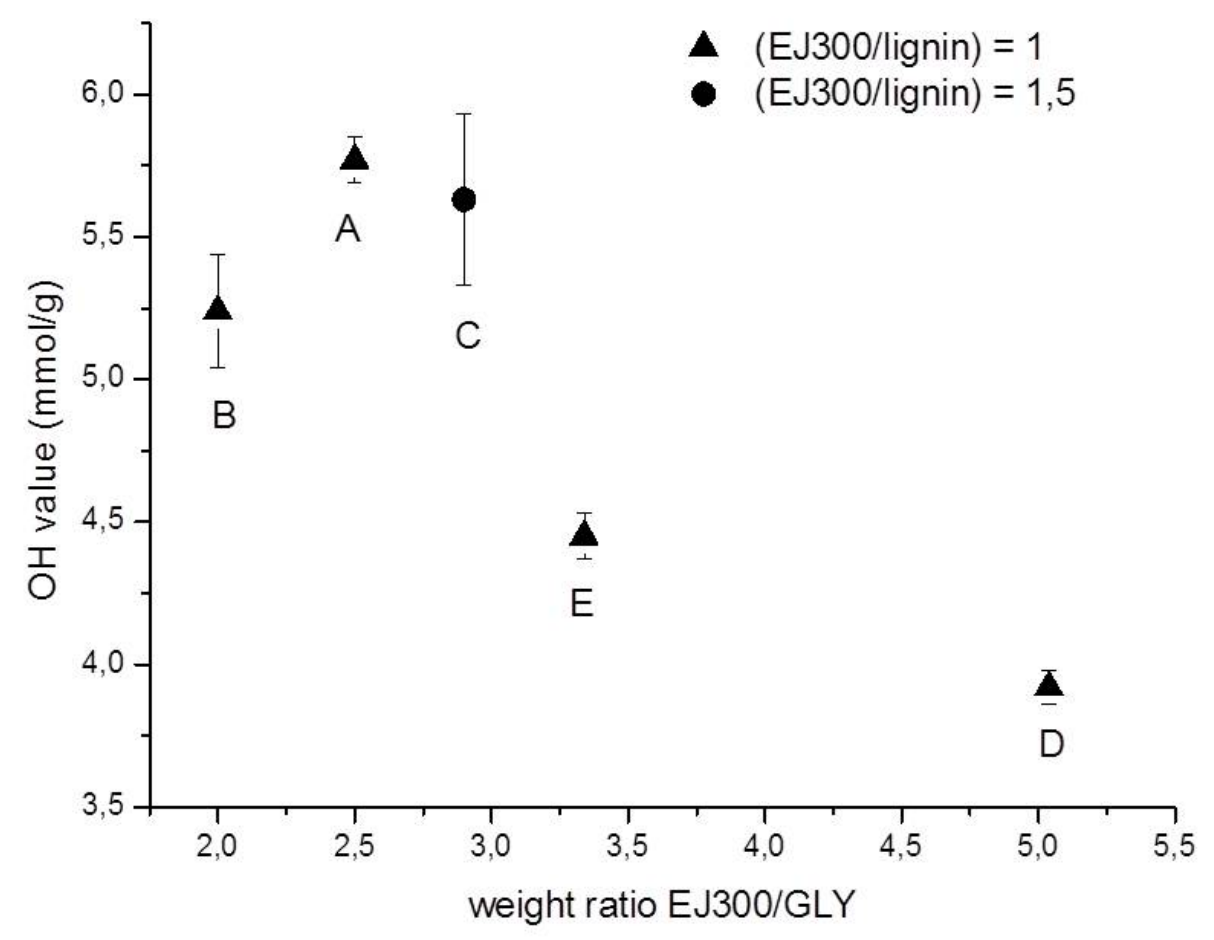

Figure 5. OH value of liquefied lignin as a function of the EJ300/GLY weight ratio

Hence the maximum efficiency in liquefying activity was achieved in almost equimolar conditions. When the content of glycerol is lower than the content of EJ300 (A, C, E and D 
mixtures were obtained in these conditions), the excess of the epoxide groups most likely reacts with lignin. When the glycerol content is slightly higher than the EJ300 (B mixture) content, it is possible that a reaction occurs, resulting in more sterically-hindered molecules or macromolecules, which are less efficient in lignin liquefaction.

\section{Production of the polyurethane flexible foam}

Liquefied lignin is rich in hydroxyl groups but has high viscosity and hydroxyl values. Accordingly, it is not appropriate to produce flexible polyurethane foams. Based on these statements, the addition of a chain extender is necessary for decreasing the viscosity of the mixture and, at the same time, to increase the flexibility of the final polymer. Polypropylene glycol triol (PPG triol) was used as a chain extender thanks to its low $\mathrm{OH}$ value, high molecular weight, and average functionality of about 3 .

Based on the $\mathrm{OH}$ number data, the isocyanate index was set in the different trials by selecting the weight of isocyanate required for the foaming process. Precisely, NCO/OH indices lower than 100 were fixed in order to maintain a low cross-linking degree in the final material ${ }^{36-37}$.

The foams were produced by following the "one-shot" approach consisting of mixing all the components involved (polyols, chain extender, blowing agent, catalysts, silicon emulsifiers) with the exception of polyisocyanate and the addition of polyisocyanate. The mixing step allowed for intimate contact between the polyisocyanate and polyol. Once mixed, the liquid mixture was placed in a mold which was immediately closed, so constraining the foam to take its shape in a controlled rise expansion way.

The formation kinetics of the foam was evaluated by means of cream and rise times. Cream time is defined as the time required by the polyurethane mixture to change from a clear and dark color to a creamy one (although liquefied lignin has a very dark color, it was possible to recognize a change when cream time was reached), while the rise parameter is the time it takes the foam to completely expand. 
These two parameters are very important for checking the kinetics of the foaming process based on the reactions of Figure 2. The formulations of foams produced and the values of cream and rise times are reported in Table 1 and Figure 6, where an increase in both cream and rise time can be observed for the different formulations having, from $\mathrm{D}$ to $\mathrm{C}$, a decreasing lignin content thus showing a positive effect of lignin as a process accelerator.

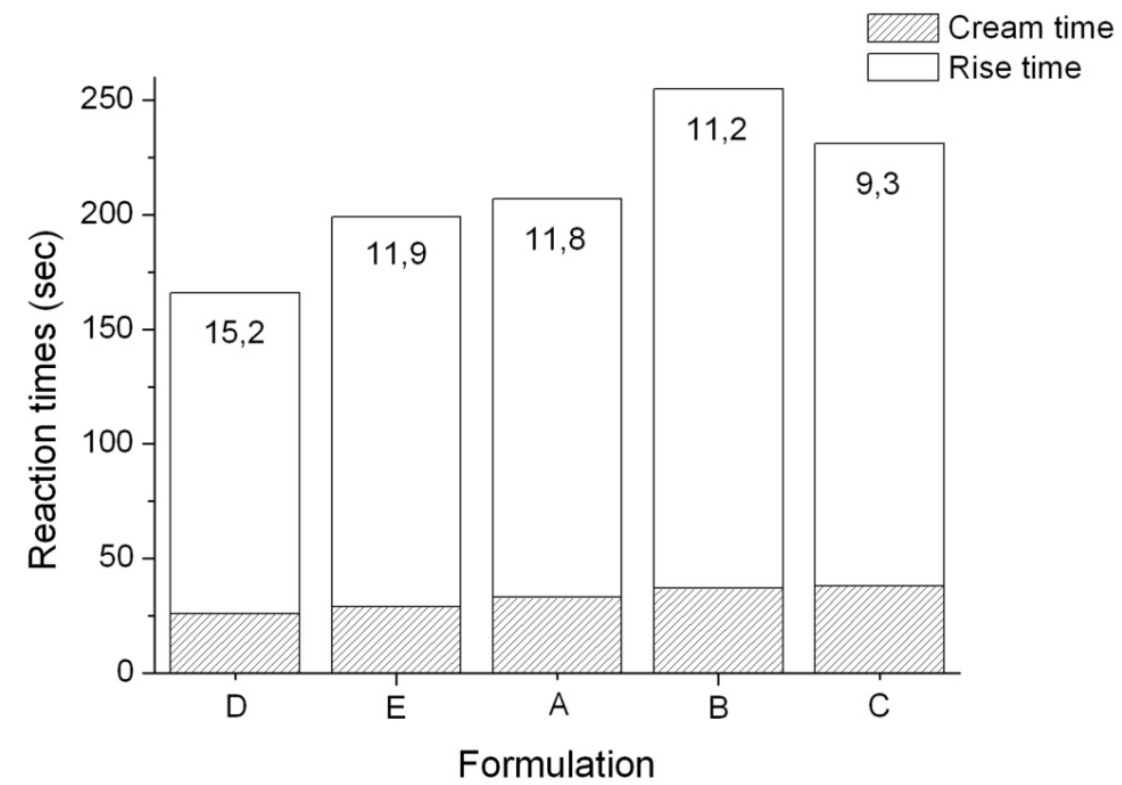

Figure 6. Cream and rise time values of produced formulations and lignin content (wt \%) at NCO/OH 70 .

\section{FT-IR Spectroscopy}

Polyurethane foams were qualitatively characterized using a FT-IR technique with the aim of assessing the presence of unreacted isocyanate inside the foams and evaluating the formation of typical urethanic bonds. Figure 7 shows the spectra of some produced foams. 

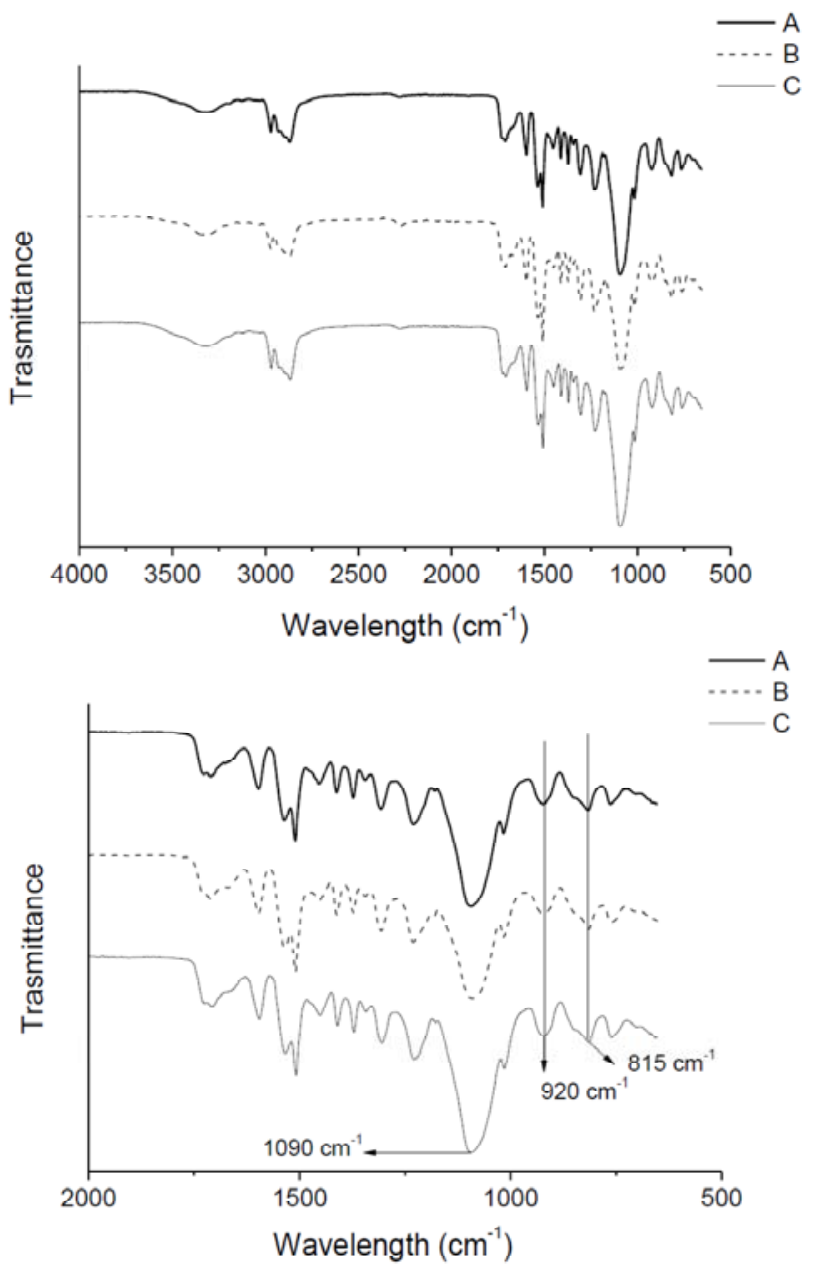

Figure 7. FT-IR spectra of polyurethane foams obtained starting from Protobind 1000 lignin and using different amounts of EJ 300 as a liquefaction solvent.

The above spectra qualitatively demonstrated the formation of urethanic linkages for each proposed formulation. In fact, in the spectra it is possible to observe the typical signal of urethanic linkages, such as the $-\mathrm{NH}$ vibrational stretching $\left(3500-3200 \mathrm{~cm}^{-1}\right)^{38}$ and the $-\mathrm{CO}$ characteristic vibration $\left(1730-1640 \mathrm{~cm}^{-1}\right)^{39}$. Specifically, three absorption bands can be found in this region: the first, at about $1550 \mathrm{~cm}^{-1}$, is typical of $-\mathrm{CN}$ urethanic linkage ${ }^{5}$, and the other ones are attributable to $-\mathrm{CO}$ stretchings ${ }^{40}$. The absorption peak at about $1620 \mathrm{~cm}^{-1}$ is characteristic of bidentate urea that interacts with surrounding molecules by means of hydrogen bonds, meanwhile the second one, at about $1710 \mathrm{~cm}^{-1}$, is attributable to the presence of free urea. These hydrogen bonds of urea, either bidentate or monodentate, are a 
clear indication of the presence of a hard domain inside the foam structure. Peaks at 920 and $815 \mathrm{~cm}^{-141}$ attributable to epoxide rings could be evidenced in the spectra.

On each curve, it is also possible to observe the main absorption peak of unreacted polyisocyanate at about $2270 \mathrm{~cm}^{-1} 42$; this is probably due to the steric hindrance of lignin and PMDI structures that prevented a good diffusion of polyolic reagents in the reaction mixtures. In addition, the signals below $1600 \mathrm{~cm}^{-1}$ are typical of the fingerprints of the polyurethanes ${ }^{43}$. Overall, in the framework of the investigated compositions, the infrared analysis of the flexible foams resulted in a good agreement with the reaction schemes shown in Figure 2 and Figure 4.

Thermo gravimetric analysis

Thermogravimetry is a very practical technique for analyzing the thermal degradation of polyurethanic materials based on renewable sources ${ }^{44-47}$. Figure 8 reports the thermogravimetric curves of some produced foams.

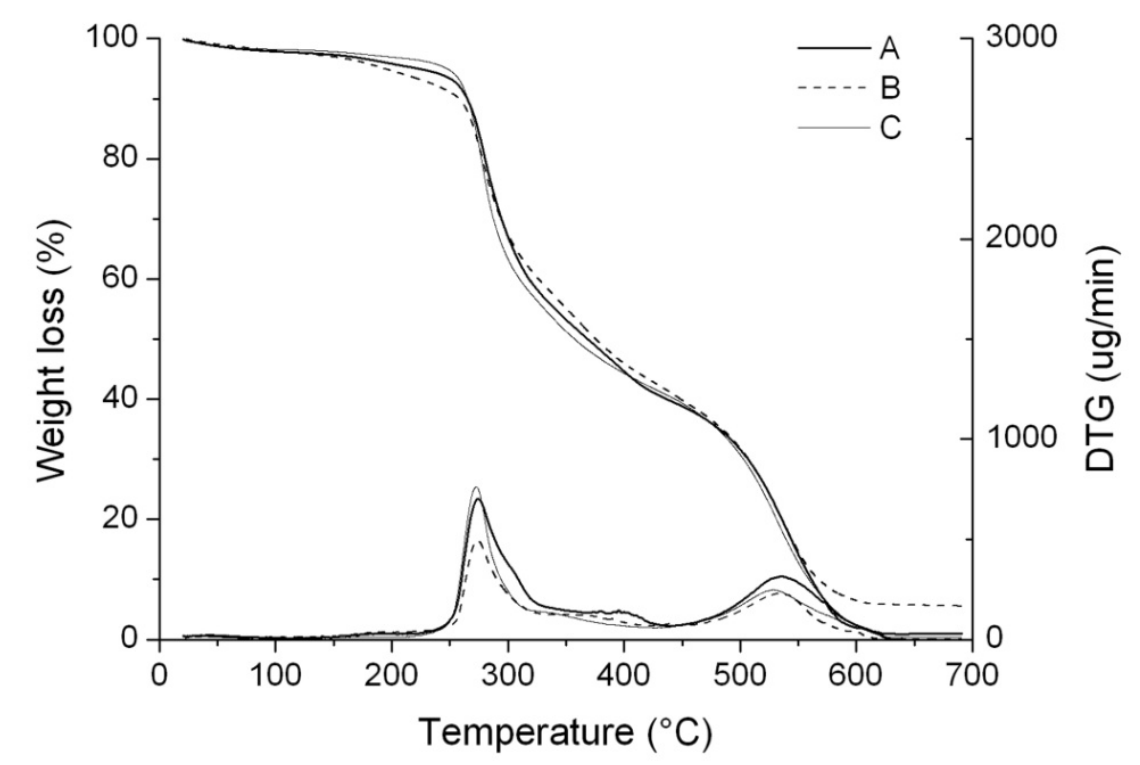

Figure 8. TGA curves of different types of produced polyurethane foams at isocyanate index 80 .

The thermograms show three typical steps for each reported formulation: the first, at about $270{ }^{\circ} \mathrm{C}$, is characteristic of the irreversible degradation of urethanic bond, while the others, at 
about $375{ }^{\circ} \mathrm{C}$ and $540{ }^{\circ} \mathrm{C}$, are related to a phase separation inside of the material, connected to the degradation of soft blocks and hard blocks ${ }^{48}$, respectively.

In good agreement with infrared spectroscopy results, the use of EJ 300 as a liquefaction solvent did not influence the thermochemical behavior and the urethanic content of the foams. A similar consideration can be made looking at the amount of the two solvents and at the type of lignin.

\section{Dynamic mechanical thermal analysis}

DMTA is a widely used technique to examine the viscoelastic features of flexible polyurethane foams. Figures 9 and 10 show the storage modulus profile and the $\tan \delta$ trend, respectively.
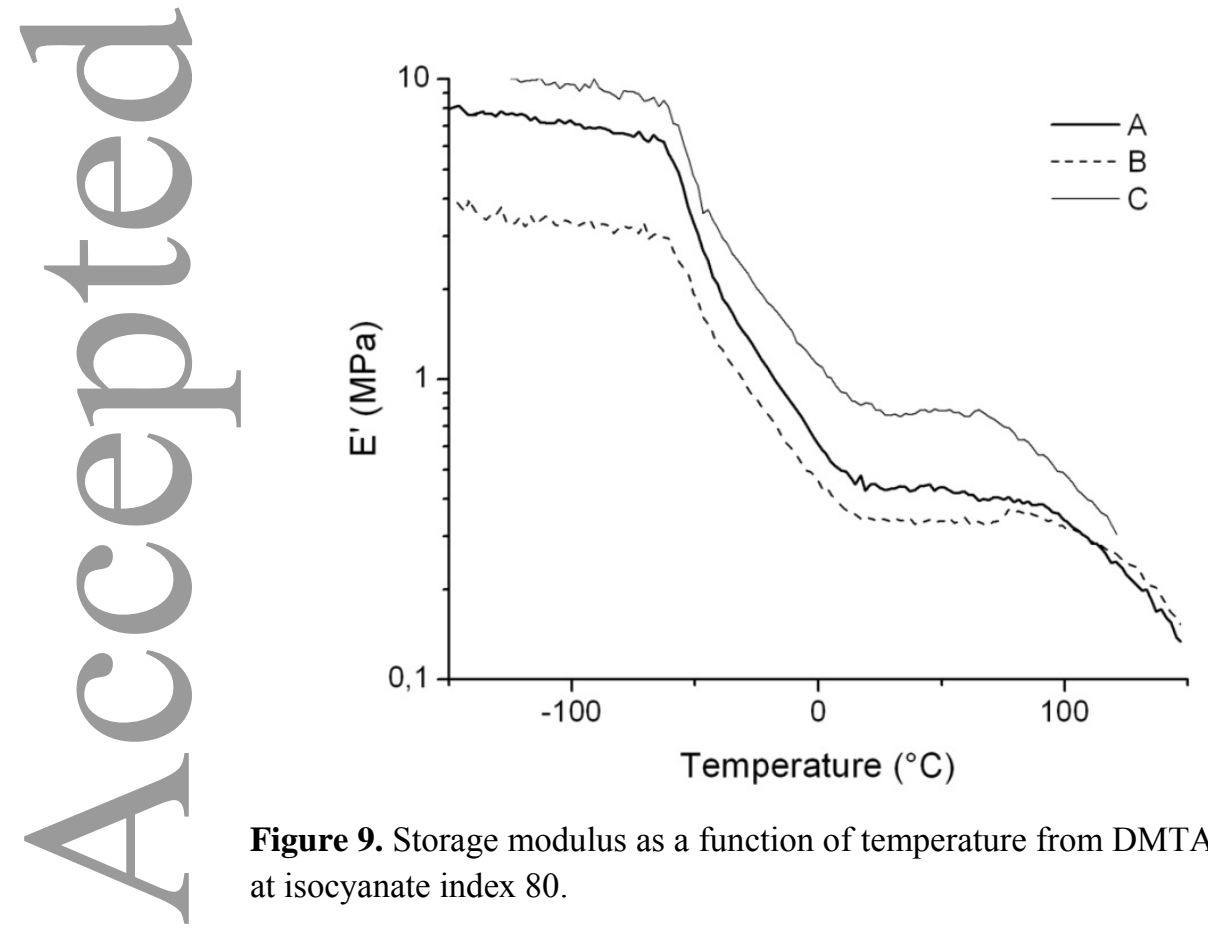

Figure 9. Storage modulus as a function of temperature from DMTA experiments carried out on different foams at isocyanate index 80 . 


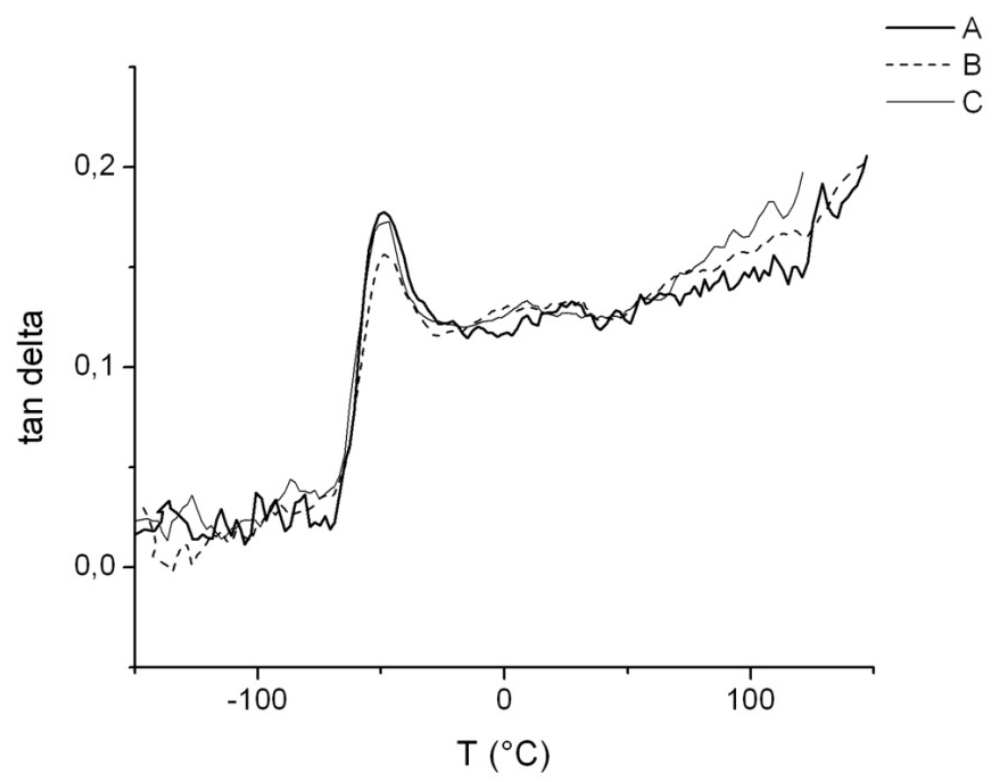

Figure 10. Tan $\delta$ as a function of temperature from DMTA experiments carried out on different foams at isocyanate index 80 .

Storage modulus profiles show two different transitions: one attributable to the flexible segments and the other related to the hard segments. Both domains present their own mechanical stiffness and glass transition temperatures $\left(\mathrm{T}_{\mathrm{g}}\right)^{49}$. The soft phases (also called polyol-rich domains) have a low $\mathrm{T}_{\mathrm{g}}$ (usually between $-70{ }^{\circ} \mathrm{C}$ and $-50{ }^{\circ} \mathrm{C}$ ), which imparts its visco-elastic properties to the foam, thus allowing absorption and dissipation of energy. In comparison, the hard phases (also called polyurea-rich domains) have a higher $\mathrm{T}_{\mathrm{g}}$ (about 80$100{ }^{\circ} \mathrm{C}$ ) and give greater modulus and thermal stability to the foams ${ }^{50}$. A similar trend was observed for every sample analyzed, regardless of the different weight ratios among polyolic reagents and isocyanate fractions.

Based on these statements, it is possible to affirm that the thermal properties of the polyurethane foams produced starting from commercial soda lignin and by using EJ 300 as a liquefaction solvent did not significantly change by changing the ratios of the polyolic components. Furthermore, these properties are comparable with those related to foams produced starting from fossil sources ${ }^{51}$. 
In detail, Figure 9 shows, for each formulation, a plateau related to the properties of polyurethane material above $0^{\circ} \mathrm{C}^{52}$. Interestingly, the end of the plateau, which can be considered the maximum temperature for material application, is higher in the foams having the highest lignin content (A and B).

The $\tan \delta$ graph (Figure 10) shows a similar value of $\mathrm{T}_{\mathrm{g}}$ (about $-50{ }^{\circ} \mathrm{C}$ ) for each kind of investigated foam in accordance with expectation ${ }^{12}$. This $T_{g}$ is related to the soft phase and remains approximately the same regardless of the decrease in lignin content in the foams; this is because lignin is part of the hard domain, and therefore its content does not affect the thermo-dynamic properties. The heights of those peaks at glass transition temperature decreased by decreasing the lignin content and thus increasing the mobility of the system ${ }^{53}$. A very small peak due to the release of carbon dioxide from the foam cells was observed ${ }^{54}$.

\section{Mechanical properties and morphology}

The apparent densities of the foams produced are reported in Table 3 and Figure 11, where a nonlinear correlation between isocyanate index and apparent density for each starting formulation can be observed.

A trend with a minimum could be tentatively observed as a function of the isocyanate index, which is probably explainable if considering that the density is the result of the foaming process, much influenced by the evolution, during reaction time, of $\mathrm{CO}_{2}$ and of viscosity, with the process ending when the increased viscosity inhibits macromolecular mobility. Carbon dioxide content can be increased by increasing the $\mathrm{NCO} / \mathrm{OH}$ value (increasing viscosity and thus reducing density thanks to a better incorporation of $\mathrm{CO}_{2}$ bubbles), but the density decreases up to a minimum. In fact, the viscosity is the consequence of both the starting viscosity of polyols and successive reactivity of polyisocyanate with $-\mathrm{OH}$ and $-\mathrm{NH}_{2}$, with the latter being predominant ${ }^{55}$ in the case of a high isocyanate index. This latter reactivity contributes to reduce the foam expansion above the minimum. 


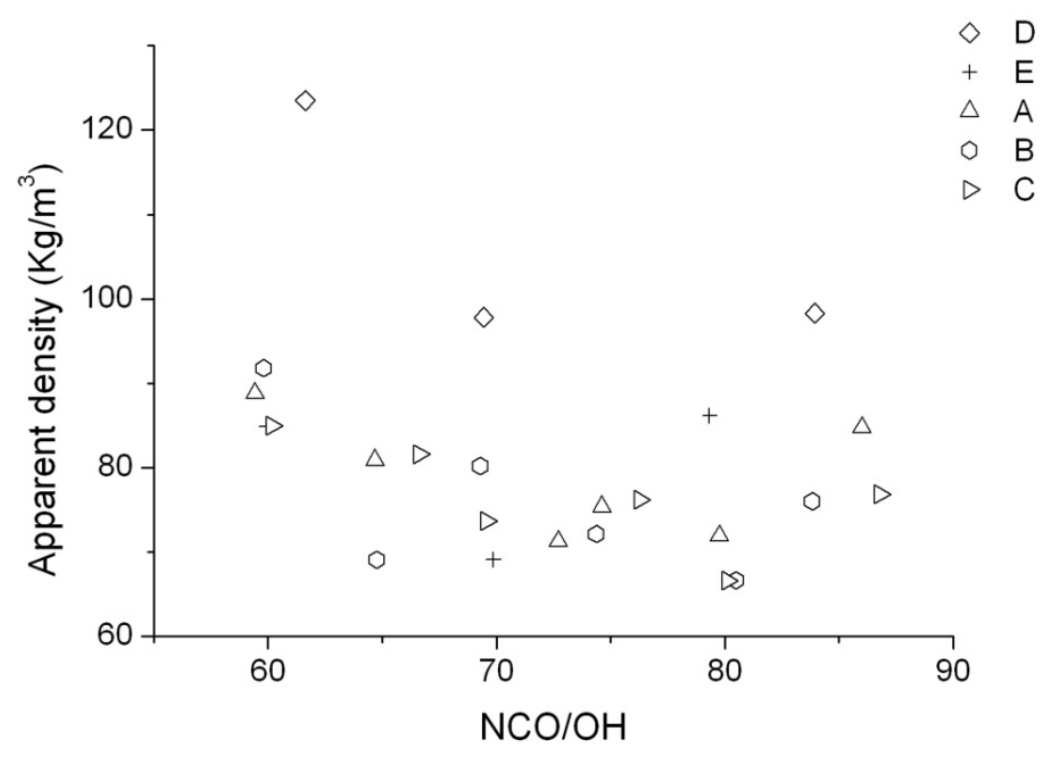

Figure 11. Correlation between apparent density and $\mathrm{NCO} / \mathrm{OH}$ for all polyurethane foams produced

This trend does not have a direct influence on the mechanical results. In fact, Figure 12 shows a direct proportionality between the isocyanate index and $C F D V$, which was obtained by following the ASTM norm D 3850-94 and represents the force necessary to produce the 50\% compression of the specimen's thickness. This value is related to flexibility, increases with the foam stiffness and by increasing the total lignin content in the final foam. In this sense, higher values of compression strength indicate that the foam is more resistant, and this resistance results from both higher crosslinking density and greater apparent density. 


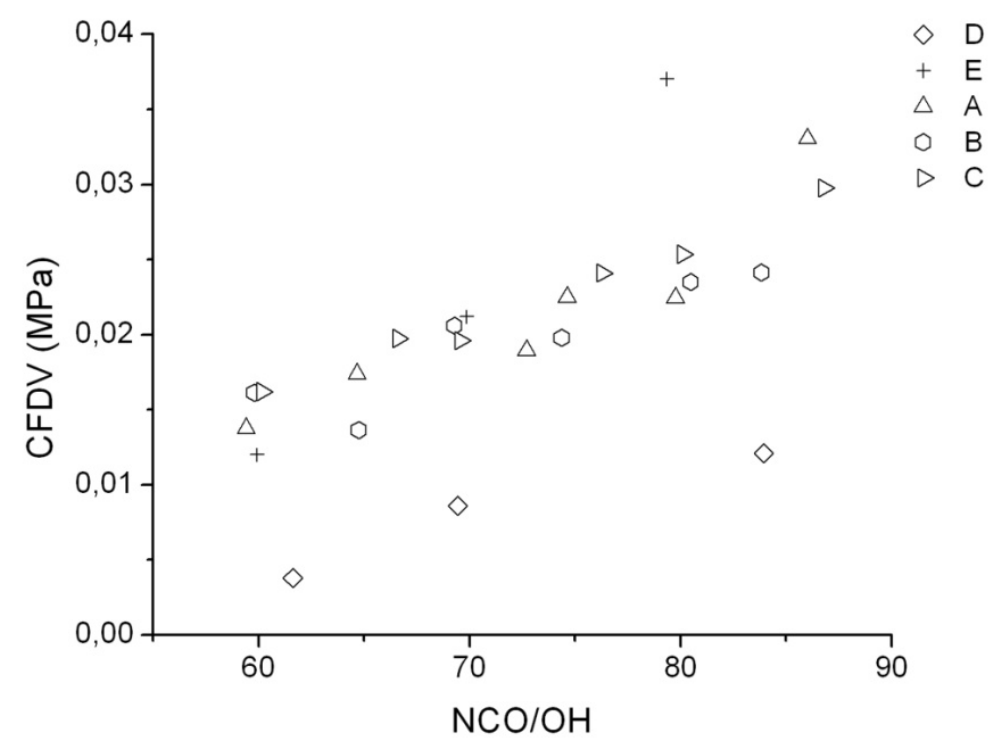

Figure 12. Correlation between $C F D V$ and isocyanate index for polyurethane foams produced.

This linear increasing is in agreement with what expected because a greater content of polyisocyanate means a higher amount of crosslinking within the material, which imparts lower flexibility to the polymeric structure.

The loss in thickness in the second compression step is a further important parameter to check during the optimization of this process because its lowering results in better mechanical performance. In this sense, all the formulations produced present an average value of $1.5 \%$ in agreement with the accepted standard for the marketing of this kind of products.

Taking into account the required commercial characteristics, flexible foams should have a compression strength value between 0.01 and $0.07 \mathrm{MPa}^{12}$, therefore all the formulations produced resulted within this approved range.

Scanning Electron Microscopy (SEM) investigations allowed for characterizing polyurethane foams from a morphologic point of view, considering that the foams' mechanical properties are also influenced by the thickness and size of the cells ${ }^{56}$. The main goal of microscopic characterization is to demonstrate the presence of open cell structure, which is characteristic 
of flexible polyurethane foams. SEM micrographs of A, B and C formulations are reported in Figure 13.



Figure 13. SEM micrographs (50x) of some flexible polyurethane foams produced.

As expected, these characteristic formulations presented quite open cell structures with polyhedral shapes and showed a preferential orientation related to the foam rise direction. By increasing the amount of EJ300 (C mixture), it is possible to observe a reduction in cell size and a lower number of completely open cells. As it can be seen, some of the intercellular membranes are not entirely broken insofar as the foams present a very low content of closed cells, probably because of the reactivity of EJ 300, which was reactive in the microwave oven during the liquefaction step resulting in a higher formation of linkages, especially by grafting to lignin.

Figure 14 reports SEM micrographs of formulation B at different isocyanate indices.

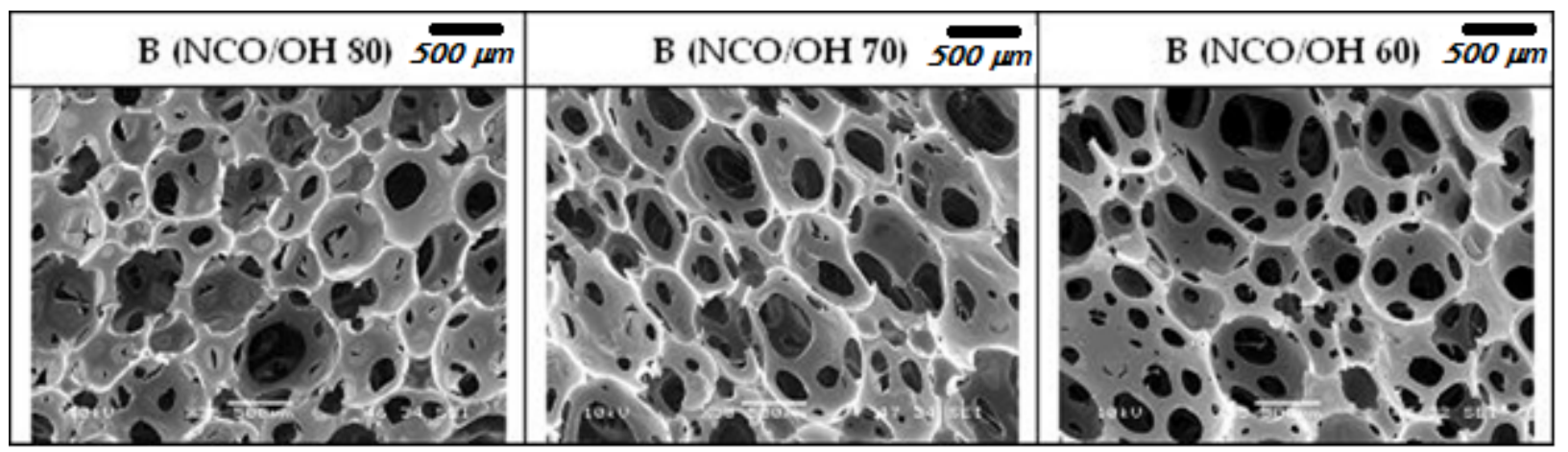

Figure 14. SEM micrographs (35x) for comparing the formulations produced at the same isocyanate index.

Figure 14 shows that by decreasing the isocyanate index (i.e. from 80 to 60 ) it is possible to obtain structures with more open cells, despite a more irregular cell size; this greater opening 
is perfectly in agreement with the behavior of flexible foams ${ }^{57}$. By decreasing the isocyanate index, it is possible to obtain foams with bigger cells, and their dimensions are a useful parameter for explaining the flexibility of the material. In this sense, foams with smaller and more compact cells present higher values of storage modulus, which are directly related to the rigidity of the material. This picture is in agreement with what is shown in Figure 11, indeed a higher $\mathrm{NCO} / \mathrm{OH}$ value led to a lower density thanks to the increase in viscosity up to a minimum.

\section{Conclusion}

Based on a previously developed green method, this study reports on the successful synthesis of flexible polyurethane foams starting from commercial soda lignin by following an environmentally- sustainable pathway based on microwave irradiation for liquefying lignin and on the use of water as only a blowing agent. A particular glycerin polyglycidyl ether (EJ 300) was used with Glycerol as liquefaction solvents and polypropylene glycol triol (PPG triol) as a chain extender. EJ 300 was activated by glycerol thus resulting in compounds having both the capability of liquefying lignin and grafting onto it. The foams were produced in a controlled rise expansion, thus achieving the required specifics for the final materials. The foams were produced by means of "one-shot" approach maintaining an isocyanate index of less than 100 in order to lower the crosslinking degree.

Compared to the starting amount of lignin, at least $40 \%$ by weight of glycerol and $100 \%$ by weight of EJ 300 should be employed to obtain foams with good mechanical and chemical properties. Such a study allowed to raise the lignin amount in the final foams up to about $12 \%$ and to heighten the amount of renewable sources up to about $30 \%$ by weight, consequently partially replacing fossil polyols. All the foams had an apparent density ranging between 65 and $95 \mathrm{~kg} / \mathrm{m}^{3}$, a compression strength value between $1.3510^{-2}$ and $3.3510^{-2} \mathrm{MPa}$, and an 
average thickness loss less than $1.5 \%$. When compared with commercial standards, the three proposed formulations showed satisfactory properties for packaging purposes, i.e. in packaging furniture and car seat interiors.

To conclude, replacing PEG\#400 ${ }^{12}$ with EJ 300 as one of liquefaction solvents introduced a molecule capable of behaving both as a liquefying solvent and a flexible extender of lignin, as well as improved the properties of the foams regarding apparent density and $C F D V$.

Therefore glycerin polyglycidyl ether, when activated by glycerol, is a suitable component for preparing a polyolic mixture with the aim of producing flexible polyurethane foams employing lignin.

Currently the cost of traditional cheap polyol for flexible foams is about $20 \%$ less expensive than EJ300. However the addiction of the more expensive additive can be compensated by the employment of glycerol and lignin, being much cheap. The former can be recovered as waste of the fat industry, the latter of the paper-making industry, and both are by-products of the production of bioethanol from ligno-cellulosic biomass.

\section{References}

[1] Meier MAR, Metzger JO and Schubert US, Chem Soc Rev 36: 1788-1802 (2007)

[2] Petrovic ZS, Polym Rev 48: 109-155 (2008)

[3] Hu S, Wan C and Li Y, Bioresour Technol 103: 227-233 (2012)

[4] Fan H, Tekeei A, Suppes GJ and Hsieh FH, J Appl Polym Sci 127: 1623-1629 (2013)

[5] Tu YC, Suppes GJ and Hsieh FH, J Appl Polym Sci 11: 1311-1317 (2009)

[6] Zhang L, Zhang M, Hu L and Zhour Y, Ind Crops Prod 52: 380-388 (2014)

[7] Windesein E and Wegener G, Lignin as building unit for polymers, in Polymer Science: A comprehensive references, ed by Matyjaszewski K and Möller M. Elsevier 
Science Publisher, Amsterdam, pp 255-265 (2012)

[8] Ahvazi B, Wojciechowicz O, Ton-That TM and Hawari J, J Agric Food Chem 59: $10505-10516(2011)$

[9] Laurichesse S and Avérous L, Prog Polym Sci 39: 1266-1290 (2014)

[10] Glasser W, Barnett PC, Muller PC and Sarkanen KV, J Agric Food Chem 31: 921$930(1983)$

[11] Belgacem MN and Gandini A, Monomers, Polymers and Composites from Renewable Resources, ed by Elsevier Science, Oxford, (2008)

[12] Bernardini J, Cinelli P, Coltelli MB and Lazzeri A, Eur Polym J (2014), doi: http://dx.doi.org/10.1016/j.eurpolymj.2014.11.039

[13] Pan X, Kadla JF, Ehara K, Gilkes N, Saddler JN, J Agric Food Chem 54: 5806-5813 (2006)

[14] Freudenberg K, Nature 183: 1152-1155 (1959)

[15] Crestini C, Melone F, Sette M and Saladino R, Biomacromolecules 12: 3928-3935 $(2011)$

[16] Lange H, Decina S and Crestini C, Eur Polym J 49: 1151-1173 (2013)

[17] Stewart D, Ind Crops Prod 27: 202-207 (2008)

[18] Lora JH and Glasser WG, J Polym Environ 10: 39-48 (2002)

[19] Cateto CA, Barreiro MF, Rodrigues AE, Brocher-Salon MC, Thielemans W and Belgacem MN, J Appl Polym Sci 109: 3008-3017 (2008)

[20] Grand View Research, Polyurethane (PU) Market Analysis By Product (Rigid Foam, Flexible Foam, Coatings, Adhesives \& Sealants, Elastomers), By End-use (Furniture and Interiors, Construction, Electronics \& Appliances, Automotive, Footwear, Packaging) And Segment Forecasts To 2020, ISBN Code: 978-1-68038-262-4, 2014

[21] Hatakeyama H, Polyurethanes containing lignin, in Chemical modification, properties 
and usage of lignin, ed by Hu TQ. Kluwer Academic Publishers, Springer, New York, pp 41-56 (2002)

[22] Hatakeyama T, Matsumoto Y, Asano Y and Hatakeyama H, Thermochim Acta 416: $29-33(2004)$

[23] Li Y and Ragauskas AJ, J Wood Chem Technol 32: 210-224 (2012)

[24] Cinelli P, Anguillesi I and Lazzeri A, Eur Polym J 49: 1174-1184 (2013)

[25] Zhang L, Guo X, Yan F, Su M and Li Y, J Hazard Mater 149: 675-679 (2007)

[26] Krzan A and Kunaver M, J Appl Polym Sci 101: 1051-1056 (2006)

[27] Xie J, Qi J, Hse CY and Shupe TF, BioResources 9: 578-588 (2014)

[28] Ouyang X, Lin Z, Yang D and Qiu X, Holzforschung 65: 697-701 (2011)

[29] Wang Z, Xu S, Hu WP and Xie YJ, BioEnergy Res 6: 896-902 (2013)

[30] Appleton TJ, Colder RI, Kingman SW, Lowndes IS and Read AG, Applied Energy 81: $85-113(2005)$

[31] Hassan EM and Shukry N, Ind Crops Prod 27: 33-38 (2008)

[32] Hu S and Li Y, Bioresour Technol 161: 410-415 (2014)

[33] Kunaver M, Medved S, Cuk N, Jasiukaitytè E, Poljansek I and Strnad T, Bioresour Technol 101: 1361-1368 (2010)

[34] Hu S, Luo X and Li Y, ChemSusChem 7: 66-72 (2014)

[35] Verborgt $\mathrm{J}$ and Webb AA, Diols formed by ring-opening of epoxies. US Patent $7241504(2007)$

[36] Ilaboya R, Umukoro L, Omofuma FE and Atikpo E, World Appl Sci J 14: 167-174 (2011)

[37] Prociak A, Rojek P and Pawlik H, J Cell Plast 48: 489-499 (2012)

[38] Tsai YM, Yu TL and Tsieng YH, Polym Int 47: 455-460 (1998)

[39] Boeriu CG, Bravo D, Gosselink RJ and Van Dam JE, Ind Crops Prod 20: 205-218 
(2004)

[40] Zhang XD, Bertsch LM, Makosco CW, Turner RB, House DW and Scott RV, Cell Polym 17: 327-349 (1998)

[41] Liu Y, Hu W, Lu Z and Li CM, Med Chem Commun 1: 132-135 (2010)

[42] Cole KC and Van Gheluwe P, J Appl Polym Sci 34: 395-407 (1987)

[43] Lopes RV, Osorio LF, Santos ML and Sales MJ, Macromol Symp 319: 173-178 (2012)

[44] Petrovic ZS, Zavargo Z, Flynn JH and Macknight WJ, J Appl Polym Sci 51: 1087$1095(1994)$

[45] Hablot E, Zheng D, Bouquey M and Avérous L, Macromol Mater Eng 293: 922-929 (2008)

[46] D’Souza J, Camargo R and Yan N, J Appl Polym Sci 131: 40599/1-40599/10 (2014)

[47] Hirose S, Kobashigawa K, Izuta Y and Hatakeyama H, Polym Int 47: 247-256 (1998)

[48] Satheesh Kumar MN and Siddaramaiah ER, J Appl Polym Sci 106: 3521-3528 (2007)

[49] Huh DS and Cooper SL, Polymer Engineering \& Science 11: 369-376 (1971)

[50] Aneja A and Wilkes GL, Polymer 43: 5551-5561 (2002)

[51] Kang SM, Lee SJ and Kim BK, eXPRESS Polym Lett 6: 63-69 (2012)

[52] Eceiza A, Martin MD, de la Caba K, Kortaberria G, Gabilondo N, Corcuera MA and Mondragon I, Polymer Engineering \& Science 48: 297-306 (2008)

[53] Silverajah VG, Ibrahim NA, Yunus WW, Hassan HA and Woei CB, Int J Mol Sci 13: $5878-5898(2012)$

[54] Das S, Dave M and Wilkes GL, J Appl Polym Sci 112: 299-308 (2009)

[55] Li ZF, Li JY, Yuan W, Sun BQ, Zhang FT and Wang ZL, Front Mater Sci China 2: 99-104 (2008)

[56] Gibson LJ and Ashby MF, Cellular solids: structure and properties. Cambridge 


\begin{tabular}{|c|c|c|c|c|c|}
\hline & \multicolumn{5}{|c|}{ Formulation } \\
\hline & D & $\mathbf{E}$ & $\mathbf{A}$ & B & C \\
\hline Lignin & 1 & 1 & 1 & 1 & 1 \\
\hline Glycerol & 0.2 & 0.3 & 0.4 & 0.5 & 0.5 \\
\hline EJ 300 & 1 & 1 & 1 & 1 & 1.5 \\
\hline PPG triol & 2.75 & 2.88 & 3 & 3.13 & 3.75 \\
\hline Water & 0.15 & 0.15 & 0.16 & 0.17 & 0.20 \\
\hline $\begin{array}{l}\text { DABCO NE1070 } \\
\text { (gelling) }\end{array}$ & 0.07 & 0.07 & 0.07 & 0.08 & 0.09 \\
\hline $\begin{array}{l}\text { DABCO NE300 } \\
\text { (blowing) }\end{array}$ & 0.07 & 0.07 & 0.07 & 0.08 & 0.09 \\
\hline Surfactant & 0.04 & 0.04 & 0.04 & 0.04 & 0.05 \\
\hline Isocyanate & $1.1-1.5$ & $2.5-3.3$ & $2.3-3.5$ & $2.5-3.8$ & $3.1-4.7$ \\
\hline $\begin{array}{l}\text { Lignin (\% by } \\
\text { weight) }\end{array}$ & $14.8-15.5$ & $11.4-12.5$ & $11.1-12.4$ & $10.5-11.8$ & $8.6-9.7$ \\
\hline Cream time (s) & 26 & 29 & 33 & 37 & 38 \\
\hline Rise time (s) & 166 & 199 & 207 & 255 & 231 \\
\hline
\end{tabular}

Table 1. Formulations (g) used to synthesize flexible polyurethane foams and values of cream and rise time (s).

\begin{tabular}{|c|c|c|}
\hline & Lignin liquefied $\mathrm{OH}$ value (mmol/g) & $\begin{array}{c}\text { Lignin liquefied/chain extender } \mathrm{OH} \\
\text { value (mmol/g) }\end{array}$ \\
\hline $\mathrm{D}$ & $3.82 \pm 0.06$ & $1.5 \pm 0.3$ \\
\hline $\mathrm{E}$ & $4.45 \pm 0.08$ & $3.4 \pm 0.3$ \\
\hline A & $5.77 \pm 0.08$ & $3.0 \pm 0.2$ \\
\hline B & $5.2 \pm 0.2$ & $3.2 \pm 0.2$ \\
\hline $\mathrm{C}$ & $5.6 \pm 0.3$ & $3.2 \pm 0.3$ \\
\hline
\end{tabular}

Table 2. OH values of liquefied lignin and liquefied lignin/chain extender mixture calculated by titration.

\begin{tabular}{|c|c|c|c|c|c|c|c|c|c|}
\hline Sample & $\begin{array}{c}\text { Apparent } \\
\text { density } \\
\left(\mathrm{kg} / \mathrm{m}^{3}\right) \\
\end{array}$ & Sample & $\begin{array}{c}\text { Apparent } \\
\text { density } \\
\left(\mathrm{kg} / \mathrm{m}^{3}\right) \\
\end{array}$ & Sample & $\begin{array}{c}\text { Apparent } \\
\text { density } \\
\left(\mathrm{kg} / \mathrm{m}^{3}\right) \\
\end{array}$ & Sample & $\begin{array}{c}\text { Apparent } \\
\text { density } \\
\left(\mathbf{k g} / \mathrm{m}^{3}\right)\end{array}$ & Sample & $\begin{array}{c}\text { Apparent } \\
\text { density } \\
\left(\mathrm{kg} / \mathrm{m}^{3}\right)\end{array}$ \\
\hline D85 & - & E85 & - & A85 & 84.8 & B85 & 76.0 & $\mathrm{C} 85$ & 76.9 \\
\hline D80 & 98.3 & E80 & 86.2 & A 80 & 71.9 & B80 & 66.7 & $\mathrm{C} 80$ & 66.6 \\
\hline D75 & - & E75 & - & A75 & 75.4 & B75 & 72.1 & $\mathrm{C} 75$ & 76.2 \\
\hline D70 & 97.8 & E70 & 69.1 & A70 & 71.3 & B70 & 80.2 & $\mathrm{C} 70$ & 73.7 \\
\hline D65 & - & E65 & - & A65 & 80.9 & B65 & 69.1 & C65 & 81.6 \\
\hline D60 & 123.5 & E60 & 84.9 & A60 & 88.8 & B60 & 91.8 & C60 & 85.0 \\
\hline
\end{tabular}

Table 3. Apparent density values of foams prepared with different ratios of polyol mixture in controlled expansion. 